\title{
Partnerships with local organisations are vital for conducting health research in Syria-personal reflections
}

\author{
Abdulkarim Ekzayez (1)
}

\begin{abstract}
Throughout the 9 years of the Syrian conflict, humanitarian actors have accumulated enormous experience of dealing with this complex environment and collected substantial data-only a tiny fraction, however, is being used in informing practice and research. Partnering with academic institutions could enable these actors to foster their efforts in data collection, analysis and research production. These partnerships should go beyond the traditional understanding of partnerships to include elements of a two-way capacity strengthening paradigm, and equal benefits and opportunities. Drawing on my personal experience of providing clinical medicine in field hospitals in conflict-affected areas in Syria, as well as my experience in the humanitarian response there working with Save the Children and a number of local organisations, and then moving to policy and research working with London School of Hygiene and Tropical Medicine, Chatham House and King's College London, I conclude equal partnerships and effective collaborations between academic institutions and humanitarian actors could provide a concrete and sustainable approach of conducting health research in conflict settings.
\end{abstract}

\section{Introduction}

The Syrian crisis enters another devastating phase with tragic humanitarian consequences for innocent civilians who continue to bear the brunt of an incredibly complex and protracted war. As the conflict enters its ninth year, more than a half million people have been killed with 11.7 million Syrians in need of humanitarian assistance. Displacement continues to be a major challenge for the country with 5.6 million refugees and 6.6 million internally displaced persons (IDPs) (Syrian Arab Republic humanitarian needs overview 2019; UN Refugee Agency (UNHCR) 2017; Syrian Observatory for Human Rights 2015). From December 2019 to mid-February 2020 only, more than 900,000 people were forcibly displaced in northwest Syria as a result of the Government of Syria (GoS) offensive on the region (UN 2020). The conflict

Correspondence: Abdulkarim.ekzayez@kcl.ac.uk

Research for Health in Conflict in the Middle East and North Africa (R4HC-MENA), Conflict and Health Research Group, Department of War Studies, King's College London, Room K6.08, King's Building, Strand Campus, Strand, London WC2R 2LS, UK has caused severe damage not only to the country's infrastructure and health systems but also to the physical and mental health of its population. About 11.3 million Syrians required urgent health assistance (World Health Organization 2018). These dire needs are very challenging to be addressed given that more than half of the health facilities in Syria have been destroyed (World Health Organization 2018) and health workers have been fleeing the country as a result of many factors that include targeting health facilities and health personnel (Fouad et al. 2017).

To navigate this challenging environment, humanitarian actors adopted different modalities to deliver aid such as remote management and partnerships between local, regional and international humanitarian actors (Duclos et al. 2019). However, the protraction and rapid changes of this conflict impose newer humanitarian dilemmas that require better understanding on the effectiveness of these humanitarian modalities. Specifically for the health sector, to improve the humanitarian health response in Syria, and also to pave the way for a healthy 
and sustainable early recovery of the health sector in the country, we need first to assess the conflict impact on the health of affected population; second, to document good practices in the health response, lessons to be learnt and areas for improvement; and third, to conduct effectiveness evaluations with a comparative analysis with available knowledge from other contexts. All these elements require us to conduct good-quality research that inform current and future policies and practices.

The lack of evidence in this area, similar to other conflict settings, could be attributed to (1) lack of adequate support; (2) complex local research environment including access restrictions, untapped local research capability, collaborative difficulties and lack of confidence in the research process; and (3) limited application of findings, including rapidly obsolete results and lack of commitment (Martineau et al. 2017). One proposed solution to tackle some of these challenges and to fill this gap in evidence is to strengthen research partnerships between humanitarian and research institutes at both local and international levels.

I am a Syrian medical doctor and a Senior Research Associate with the Research for Health in Conflict in the Middle East (R4HC-MENA) programme, a UK Global Challenges Research Fund programme led by King's College London (KCL) in partnerships with 7 universities and several NGOs in the UK and across the Middle East. I graduated in 2010 from Aleppo University in Syria with advanced surgical training in Munster University in Germany. My residency in neurosurgery in Aleppo, Syria, was interrupted by the Syrian conflict in 2013 when I moved to northwest of Syria to work in field hospitals providing hundreds of surgeries to those in need of cerebral and spinal injuries as a result of the conflict. I went on to head the health response for Save the Children in Syria, in parallel with participating in building the health system in Idlib Governorate. By then, I identified the need for more research to inform humanitarian health policies and also to strengthen the health system in the area. Therefore, I tried to acquire academic knowledge in addition to my practical experience, and I studied for a MSc in Epidemiology at London School of Hygiene and Tropical Medicine, followed by a Leadership in International Affairs Fellowship at Chatham House focusing on global health security. Maintaining close ties with Syria, I am a trustee of two Syrian NGOs, Shafak and Eye to the Future and a volunteer consultant with Idleb Health Directorate which is the first structured health system in rebel-controlled Syria.

In the last 4 years, I have been trying to link academic institutions in the UK with humanitarian organisations in the Syrian response to conduct research related to the interaction between health and the Syrian conflict. Working with the R4HC-MENA, new partnerships were formed between some of the leading UK universities, including King's College London, Imperial College London and Cambridge University, and Hacettepe University in Ankara, American University of Beirut, Birzeit University in the West Bank and the King Hussein Cancer Centre in Amman. The network, also, includes various NGOs and local research organisations involved in providing health interventions or researching health in the region such as Médecins Sans Frontières, Syria Relief and Syria Public Health Network.

\section{The role of partnerships with local actors in research health in the Syrian conflict}

Recently, there has been increasing attention on engaging with local NGOs and affected communities in humanitarian interventions and related research (McClelland and Hill 2019). Many studies recommend more collaborations and partnerships between the global North and the global South on research in low and middle-income countries (Costello and Zumla 2000; Edejer 1999; Bradley 2008).

Last year, I attended two conferences on health in Syria that were held in Turkey and in the UK, aimed at promoting more partnerships between international and local academic and humanitarian actors. The Global Syrian Refugee Crisis: Health and Socioeconomic Perspectives, Challenges and Opportunities congress was held in Gaziantep, Turkey (14-18 October 2019), hosted by Gaziantep University; the Union of Medical Care and Relief Organisations (UOSSM), an award winning Syrian international NGO; and the US-based Global Heath consultancy firm (The Global Refugee and Migration Congress n.d.). The main objective of the conference in Gaziantep was to address the urgent needs of the Syrian refugees in Turkey and across the world. Approximately 3.5 million Syrian refugees migrated to Turkey under the Temporary Protection Policy and around 90\% currently reside in four Turkish cities; İstanbul, Gaziantep, Urfa, and Hatay. Gaziantep has the highest concentration of Syrian refugees (around 21\% of the city population consists of Syrian refugees) and Gaziantep University provides opportunities for around 60,000 Syrian refugee students to continue education as well as opportunities for Syrian academics to work at the university. However, these positive practices of addressing the refugees' needs in Turkey are not highlighted in the literature or in relevant communities of practice because of lack of local, regional and international partnerships. Speakers at this conference emphasised that such partnerships and collaborations between international and local researchers and governmental and nongovernmental practitioners are vital.

Research for Health in the Syrian Conflict conference was held at King's College London on 10 October 2019 
in partnership with UOSSM and R4HC-MENA. The conference brought together experts from academia, front-line health actors and NGOs and showcased original research on current health issues in Syria, spanning from health system governance, epidemiology to many other disciplines within global health. There were 14 research papers presented at this conference with the vast majority from Syrian diaspora and Syrians based in Syria connected via the internet. Keynote speeches from Syrian policymakers and health practitioners from the Syrian British Medical Society and Idlib Health Directorate focused on themes such as expanding health research and medical education; health system governance and adaption; health of Syrian refugees in neighbouring countries; challenges of conducting health research in the Syrian conflict; anti-microbial resistance; health governance in opposition-controlled areas; provision of healthcare under siege; mental health, noncommunicable diseases such as cancer, diabetes and hypertension; and lastly, communicable diseases such as leishmaniasis, and disability and rehabilitation.

Both conferences provided an excellent platform for Syrian local NGOs and researchers as well as the large Syrian diaspora to engage in existing and potential partnerships and collaborations between academics and practitioners. Similar messages on the importance of equal partnerships between NGOs, policy and academic institutions were repeatedly emphasised by the different presentations and speakers. At both conferences, after presenting the unique role of R4HC-MENA as a capacity strengthening programme in areas of armed conflict in the region, I was approached by a number of Syrian NGOs to support this initiative and to explore potential opportunities for partnerships with academic institutes to better use their data, generate knowledge and produce high quality research.

\section{Examples of research partnerships with local actors in Syria}

Humanitarian health actors in Syria and elsewhere are required to prioritise lifesaving and other urgent programmatic interventions-this means their research capacity strengthening efforts are very limited. Nevertheless, an increasing number of traditional humanitarian health actors are recognising the importance of health research in conflict settings especially embedded research. This is translated in various types of research outputs produced by NGOs and disseminated in a variety of forms such as MSF scientific days and academic publications by humanitarian actors. To magnify the impact of such initiatives and to ensure sustainability, these commitments to research need to be operationalised through practical solutions that include engaging in research partnerships with local actors.
In the Syrian context, some leading examples include the partnership between the Bloomberg School of Public Health at John Hopkins University, the International Rescue Committee (IRC) and the Syrian American Medical Society on a project that explored the ethical challenges faced by humanitarian health organisations in conflict settings. The project was funded by a UK government funding body-the Department for International Development (DFID), the Wellcome Trust and a charity-ELRHA. The variety of the types of actors in this partnership enabled the use of mixed research methodologies of systematic reviews, informant interviews and workshops (Johns Hopkins Bloomberg School, International Rescue Committee (IRC), Syrian American Medical Society 2019). Another example is the partnership between the Centre for Health and Human Rights at Harvard University and both the Syrian American Medical Society and the Union for Medical and Relief Organisations (UOSSM) to establish the Syrian data hub to archive a large volume of data from hundreds of sources on lessons from the Syrian war. The project, so far, had access to around 15 million patient interactions over 5 years of the Syrian conflict. Based on this data, the project aims to set up an agenda for health research in the Syrian conflict (Harvard University 2020).

\section{UOSSM's commitment to research}

UOSSM represents a leading example of a Syrian international NGO that is committed to strengthening its research capacity by engaging in the global research community. Founded in January 2012, UOSSM is a coalition of humanitarian, non-governmental and medical organisations from the USA, Canada, UK, France, Germany, Netherlands, Switzerland and Turkey. UOSSM country chapters work under a unified strategic framework to increase the effectiveness of the health humanitarian response in conflict-affected areas in Syria. Its work focuses primarily on trauma and surgical specialised care, primary and reproductive health care, mental health and supporting health governance.

UOSSM has accumulated considerable experience in collecting, analysing and disseminating health data. The organisation has partnered with several research institutes, including John Hopkins, Harvard FXB centre for health and human rights and King's College London, to conduct quantitative and qualitative research. In 2017, it established a sub-organisation called "Midmar" in Turkey dedicated for research and training. Recently, UOSSM was granted a research grant by the Grand Challenges' Canada to develop the health integrated resilience system in conflict zones through exploring ways to utilise solar energy, electric ambulances and telemedicine to improve the health response in Syria. Recognising UOSSM's commitment to research, the Conflict and Health Research Group (CHRG) at King's College London has recently engaged UOSSM in the research and practice community of the R4HC-MENA project.

\section{Conclusion}

Equal partnerships and effective collaborations between academic institutions and humanitarian actors could provide a concrete and sustainable approach of conducting health research in conflict settings. Throughout the nine years of the Syrian conflict, humanitarian actors have accumulated enormous 
experience of dealing with this complex environment and have collected substantial data-only a tiny fraction is being used in informing practice and research. Partnering with academic institutions could enable these actors to foster their efforts in data collection, data analysis and research production. These partnerships should go beyond the traditional understanding of partnerships to include elements of a two-way capacity strengthening paradigm, and equal benefits and opportunities.

Ultimately, these partnerships will have greater and more significant impact on both humanitarian assistance and knowledge generation. For example, the Safeguarding Health in Conflict, which is a group of international NGOs, academic institutes and think tanks working to protect healthcare in conflict settings, have been generating operational research on the issue of attacks on healthcare in conflict settings. The coalition and its members engaged in providing evidence-based practical solutions for healthcare protection as well as in important policy developments on this issue (About the Coalition | Safeguarding health in conflict coalition n.d.). The Syrian American Medical Society, a member of this coalition, has been leading efforts of Syrian NGOs in Syria on documentation, reporting and accountability in relation to attacks on healthcare in Syria. Another successful example is the partnership between King's College London and UOSSM using the R4HC-MENA platform. This partnership has translated in a number of joint embedded research grant applications. Recently, $\mathrm{KCL}$ and UOSSM were granted a large award on Health System Strengthening (HSS) in northern Syria which will investigate HSS interventions also support the core functionalities of the health system there. This will ensure that humanitarian and development priorities are addressed while conducting research activities.

Local actors, who played a leading role in the health response in Syria (Duclos et al. 2019), should be at the core of these efforts for these partnerships to be effective. And, considering the extreme insecurity in most conflict-affected areas in Syria, proposed partnerships would rely mostly on remote support and collaborations similar to the partnerships that emerged between international and local NGOs in the cross-border response in Syria (Diggle et al. 2017). Thus, reflecting on those partnerships the centrality of trust, conciseness of risks and opportunities, and real understanding of capacity of both sides (Howe and Stites 2019) is crucial in building and strengthening research partnerships between academic institutions, international and local NGOs.

Lastly, while this paper focuses on the role of such partnerships in the health sector in the Syrian conflict, they can also be beneficial for other sectors in other contexts. There is a growing body of evidence on the role of partnering with local researchers and humanitarian organisations to conduct more effective research projects in such settings (Cornish et al. 2017; Adams et al. 2004; Fast 2019; Almany et al. 2010). The considered reflections presented in this paper would hopefully be beneficial in improving these partnerships for better quality research and humanitarian outcomes.

\section{Abbreviations}

NGOs: Non-governmental organisations; UOSSM: The Union of Medical Care and Relief Organisations; KCL: King's College London; R4HC-MENA: Research for Health in Conflict in the Middle East and North Africa; MSF: Médecins Sans Frontières; CHRG: The Conflict and Health Research Group (at King's College London)

\section{Acknowledgements}

Not applicable

\section{Author's contributions}

It is a sole author commentary; the commentary was developed and written by $A E$. The author read and approved the final manuscript.

\section{Funding}

This publication is funded through the UK Research and Innovation GCRF Research for Health in Conflict in the Middle East and North Africa (R4HCMENA) project, developing capability, partnerships and research in the Middle and North Africa ES/P010962/1.

\section{Availability of data and materials}

No data was used merely for the purpose of this commentary.

\section{Competing interests}

The author declares that he has no competing interests.

Received: 3 December 2019 Accepted: 3 September 2020

Published online: 09 September 2020

\section{References}

About the Coalition | Safeguarding health in conflict coalition. n.d. https://www. safeguardinghealth.org/about-coalition. Accessed 23 June 2020

Adams A, Miller-Korth N, Brown D (2004) Learning to work together: developing academic and community research partnerships. Wis Med J. 103(2):15-19

Almany GR, Hamilton RJ, Williamson DH et al (2010) Research partnerships with local communities: two case studies from Papua New Guinea and Australia. Coral Reefs. 29(3):567-576. https://doi.org/10.1007/s00338-010-0624-3

Bradley M (2008) On the agenda: north - south research partnerships and agenda-setting processes. Dev Pract. 18(6):673-685. https://doi.org/10.1080/ 09614520802386314

Cornish H, Fransman J, Newman K. Rethinking research partnerships: discussion guide and toolkit. Res Evid. 2017:1-60. https://www.christianaid.org.uk/ resources/about-us/rethinking-research-partnerships. Accessed 24 June 2020

Costello A, Zumla A (2000) Moving to research partnerships in developing countries. Br Med J. 321(7264):827-829. https://doi.org/10.1136/bmj.321. 7264.827

Diggle E, Welsch W, Sullivan R et al (2017) The role of public health information in assistance to populations living in opposition and contested areas of Syria, 2012-2014. Confl Health 11(1). https://doi.org/10.1186/s13031-017-0134-9

Duclos D, Ekzayez A, Ghaddar F, Checchi F, Blanchet K (2019) Localisation and cross-border assistance to deliver humanitarian health services in North-West Syria: a qualitative inquiry for the Lancet-AUB Commission on Syria. Confl Health. 13(1):20. https://doi.org/10.1186/s13031-019-0207-z

Edejer TTा (1999) North-South research partnerships: the ethics of carrying out research in developing countries. Br Med J. 319(7207):438-441. https://doi. org/10.1136/bmj.319.7207.438

Fast L (2019) Researching local humanitarian action through partnerships with local actors, pp 1-8 https://www.odi.org/sites/odi.org.uk/files/resourcedocuments/12834.pdf. Accessed 24 June 2020 
Fouad FM, Sparrow A, Tarakji A et al (2017) Health workers and the weaponisation of health care in Syria: a preliminary inquiry for The Lancet American University of Beirut Commission on Syria. Lancet. 390(10111):25162526. https://doi.org/10.1016/S0140-6736(17)30741-9

Harvard University. Syria - FXB Center for Health \& Human Rights | Harvard University. 2020. https:/fxb.harvard.edu/syria/. Accessed 22 Feb 2020

Howe K, Stites E (2019) Partners under pressure: humanitarian action for the Syria crisis. Disasters. 43(1):3-23. https://doi.org/10.1111/disa.12298

Johns Hopkins Bloomberg School, International Rescue Committee (IRC), Syrian American Medical Society. Ethical challenges in humanitarian health in situations of extreme violence. 2019. https://humanitarianhealthethics.net.

Martineau T, Woodward A, Sheahan K, Sondorp E (2017) Health systems research in fragile and conflict affected states: A qualitative study of associated challenges. Heal Res Policy Syst 15(1). https://doi.org/10.1186/ s12961-017-0204-x

McClelland I, Hill F (2019) Exploring a strategic partnership to support local innovation. Humanit Exch Spec Featur.:21-23 https://odihpn.org/ magazine/exploring-strategic-partnership-support-local-innovation/. Accessed 6 Mar 2020

Syrian Arab Republic humanitarian needs overview. 2019 https://hno-syria.org/ \#home. Accessed 8 Jan 2020

Syrian Observatory for Human Rights. 320,000 people killed since the beginning of the Syrian Revolution. 2015. http://www.syriahr.com/en/?p=152189\&_cf chl_jschl_tk_=4769805c73d08356c684eb1cd73bca31f9b97452-15831063720-AfzbXqnkUBwFfl4j-IrA2sa4Pdzn4Yk10zAOrOdME4d4M99fR_Pj5SwKAnkrE5 gqPU8dWZmN9KDJfCXwD0mu5r2jlWekgZNnmrSHBejD7WyByx4RX5 RRiSIQaahfp9ASPh4xp-RJOYFd24GKI. Accessed 1 Mar 2020

The Global Refugee and Migration Congress - Health and socioeconomic perspectives, challenges and opportunities. n.d. https://www. syrianrefugeeconference.com/. Accessed 21 Oct 2019

UN. UN chief calls for immediate ceasefire in Syria's war-battered north-west | UN News. 2020. https://news.un.org/en/story/2020/02/1057591. Accessed 1 Mar 2020

UN Refugee Agency (UNHCR). Situation Syria regional refugee response.; 2017. https://data2.unhcr.org/en/situations/syria. Accessed 1 Mar 2020

World Health Organization. WHO EMRO | Seven years of suffering: Syria facts and figures | News | Emergencies. WHO website. 2018. http://www.emro.who.int/ eha/news/seven-years-of-suffering-syria-facts-and-figures.html. Accessed 21 Oct 2019

\section{Publisher's Note}

Springer Nature remains neutral with regard to jurisdictional claims in published maps and institutional affiliations.

\section{Submit your manuscript to a SpringerOpen ${ }^{\circ}$ journal and benefit from:}

- Convenient online submission

- Rigorous peer review

- Open access: articles freely available online

- High visibility within the field

- Retaining the copyright to your article

Submit your next manuscript at $\boldsymbol{\nabla}$ springeropen.com 